\title{
Preface
}

\section{Earth System Science Data access, distribution and use for education and research}

The present special edition deals with Earth System Science Data (ESSD) collection, distribution, archival, analysis, visualization and discovery requirements for enabling distributed and scalable solutions in the Education and Research sectors. This special edition is a compilation of a subset of papers presented at the special session of the Educational Symposium during the 2005 European Geosciences Union General Assembly in Vienna, Austria.

The manuscripts report innovative developments and experiences with promising and well-accepted technologies that enable ESSD effective access and sharing over distributed computing platforms (e.g. the Internet, the World Wide Web, open Grid platforms, etc.).

The topics covered by this publication include: Web and grid technologies, multimedia instruction, data models, ontology, interoperability and mediation solutions, Scientific Markup Languages, distributed computing, and digital libraries.

The editors believe that the publication of this special issue focused on ESSD will be a timely and topical contribution that will aid the geosciences community in the development and implementation of new technologies and strategies. These are necessary to cope with the increasing availability of high-volume and disparate data and the need for appropriate data services to use this information effectively in ed- ucation and research. The combination of the papers will provide opportunities for continued dialogue and interaction between data providers and consumers, including scientists, educators, planners, and operational practitioners. In addition to the discussion of issues, we believe it will also lead to initiating new areas where further research and development are needed.

We extend our sincere thanks to all of the authors who worked so hard to submit and revise their manuscripts, and special thanks to those who assisted us with the review process and in putting it all together.
E. Cutrim, Western Michigan University
M. Ramamurthy, Unidata/UCAR
S. Nativi, Italian National Research Council and University of Florence
L. Miller, Unidata/UCAR
Special Volume Editors 